\title{
Empirical Study on the relationship between freight volume and economic development of provinces and cities in China
}

\author{
Chu Shanshan ${ }^{1}$ \\ ${ }^{1}$ Beijing Jiaotong University School of Economics and Management Beijing, China
}

\begin{abstract}
The transportation industry is the basic and leading industry of the national economy, and it is an important pillar of the national economy. The freight transportation is an important part of the transportation and plays an important role in the economic development. At the same time, the development of freight transport itself is also affected by the economy. Therefore, this paper studies the relationship between cargo transportation and economic growth, and explores the internal relationship and law between them, so as to provide reference for the development of cargo transportation and the growth of national economy.

This paper selects the freight volume and GDP indicators of 31 provinces and cities in China from 1993 to 2018, and discusses the development trend of GDP and freight volume from the perspective of provinces and cities. The results are as follows: 1. Freight volume and GDP showed an upward trend from 1993 to 2018 , but the growth of freight volume was slower than that of GDP. 2. There is a co integration relationship between GDP and freight volume, and the national GDP increases by $0.954 \%$ for every $1 \%$ increase in freight turnover. 3 . There are differences in the driving effect of freight volume in typical regions and provinces.
\end{abstract}

\section{INTRODUCTION}

Since the reform and opening up, China's economy has made rapid development, the economic upsurge has led to the rise of transportation industry, in which the freight transportation has made a great leap. The volume of freight transportation is closely related to the development of national economy, which is an important basis for measuring the development and change of China's macroeconomy. Freight volume can fully reflect the level of economic development. Statistical data and analysis reports are available in Statistical Yearbooks of various departments and regions. According to the relevant data of freight volume and gross domestic product (GDP) released by the National Bureau of statistics from 1993 to 2018, it can be concluded that the trend of China's freight volume and economic growth is generally similar, and there is a certain coupling relationship between them.

China has a vast territory and a large population, so the demand for goods transportation only increases. With the continuous innovation and improvement of the transportation industry, the modern transportation industry is developing towards diversification and convenience, and the freight transportation is also more convenient. Does the transportation of goods also have a positive driving effect on the economic development of provinces? If so, what is the driving effect? Does it have the same coupling relationship and greater driving effect with typical regions such as Yangtze River Delta, Pearl River Delta and Northeast China? In this paper, the above issues will be explored in depth.

\section{LITERATURE REVIEW}

Tian Jun and ran Zhongming ${ }^{[1]}$ from the perspective of regional differentiation and differentiation of different modes of transportation, the empirical results show that from the national level, freight transport plays a positive role in promoting the development of urban economy, and has a significant impact. Based on the data of Hebei Province from 1990 to 2009 , Li Fen et al. ${ }^{[2]}$ studied the quantitative relationship between transportation and economic development. The results show that the mutual promotion of economic development and transportation is not the same, that is, the driving effect of transportation on economy is stronger than that of economic evelopment on transportation.

Many scholars have discussed the relationship between freight transportation and economic development from the perspective of coupling and decoupling. Based on the detailed study of decoupling phenomenon in EU countries, McKinnon ${ }^{[4]}$ and Jérôme Verny ${ }^{[5]}$ actively seek the causes of decoupling by constructing an analysis framework. As for decoupling, Alises et $\mathrm{al}^{\left[{ }^{[6]}\right.}$. studied the situation of Britain and Spain from 1999 to 2007, and found that goods turnover and GDP were coupled. Based on this, Alises \& Vassallo ${ }^{[7]}$ expanded the research object, and through the data analysis of nine European countries from 2000 to 2007, concluded that cargo transportation and economic growth also appear different degrees of decoupling theory. Based on the transportation theory, Rong Chaohe ${ }^{[8]}$ summarized the theory of decoupling 
between economic growth and freight transportation in the mature period of economic development and cargo transportation by analyzing the development characteristics of transportation in different countries in the world.

In a word, there are abundant literatures on the research of freight transportation and economic growth, but most of them are about the transportation volume of single industry or single province. The research on the whole of provinces and cities is not enough. Therefore, based on the data of 31 provinces and autonomous regions in China from 1993 to 2018, this paper verifies the relationship between freight transport volume and economic growth through empirical analysis.

\section{Methods}

\subsection{Empirical model}

In order to explore the relationship between China's GDP and freight volume, based on the relevant research ${ }^{[9]}$, this paper carries out regression analysis on the relevant panel data of 31 provinces and cities in China. According to the characteristics of panel data and related literature, this paper establishes the regression model of panel data(1).

$$
\begin{aligned}
& \ln \mathrm{GDP}_{\text {it }}=\alpha_{\mathrm{i}} \lambda_{\mathrm{t}}+\beta_{\mathrm{i}} \ln \mathrm{VT}_{\mathrm{it}}+\mu_{\mathrm{it}} \cdots(1) \\
& \mathrm{i}=1,2, \cdots \cdots 31 ; \mathrm{t}=1993,2000, \cdots \cdots 2018
\end{aligned}
$$

The GDP index in the model measures the economic development, with the unit of 100 million yuan; the VT index represents the freight volume, with the unit of 10000 tons. At the same time, the logarithm of variables in regression model is to better measure the change ratio of explained variable caused by the change percentage of explanatory variable. $\alpha_{\mathrm{i}}$ is the intercept term, which measures the individual effect of each province; $\lambda_{\mathrm{i}}$ represents the time effect; $\mu_{\mathrm{it}}$ is the random error term; I in the subscript represents different individuals, that is, different provinces; $\mathrm{t}$ is the time.

Then we use simple mixed model regression to analyze the relationship between GDP and freight volume from 1993 to 2018. After regression, the results are as follows (2).

$$
\ln \mathrm{GDP}_{\mathrm{it}}=0.954 \ln \mathrm{VT}_{\mathrm{it}}-1.818 \cdots(2)
$$

\subsection{Data resource}

Since 1993, the railway freight transport has increased the volume of luggage and parcel transportation. For the sake of data comparability and integrity, this paper selects the freight volume and GDP of various provinces and cities from 1993 to 2018 for empirical research, and the data is from the National Bureau of statistics.

\subsection{Data description}

Both freight volume and freight turnover are quantitative indicators that reflect the service provided by the freight system for economic development. The latter comprehensively considers the freight volume and its corresponding transportation distance, reflects the total achievements of freight service production, and is a more reasonable index to study the relationship between freight transportation and economic growth. However, due to the limitation of insufficient transportation distance statistics, the error of China's freight turnover statistics is large, so this paper only uses freight volume as the explanatory variable. GDP represents national economic growth as explanatory variable. In this paper, the natural logarithm of freight volume and GDP is adopted. In order to eliminate the heteroscedasticity in time series and not change the cointegration relationship, lnGDP and LNVT are used to express GDP and freight volume respectively.

\section{RESULTS AND ANALYSIS}

It can be seen from Figure 1 that the GDP of all provinces and cities shows a significant upward trend from 1993 to 2018 , but with the development of time, the differences of economic growth between provinces and cities become more and more obvious. On the whole, the economic development of the central and southern provinces and cities is better than that of the old industrial provinces and cities in the north, with Tibet, Ningxia, Qinghai and Xinjiang developing most slowly.

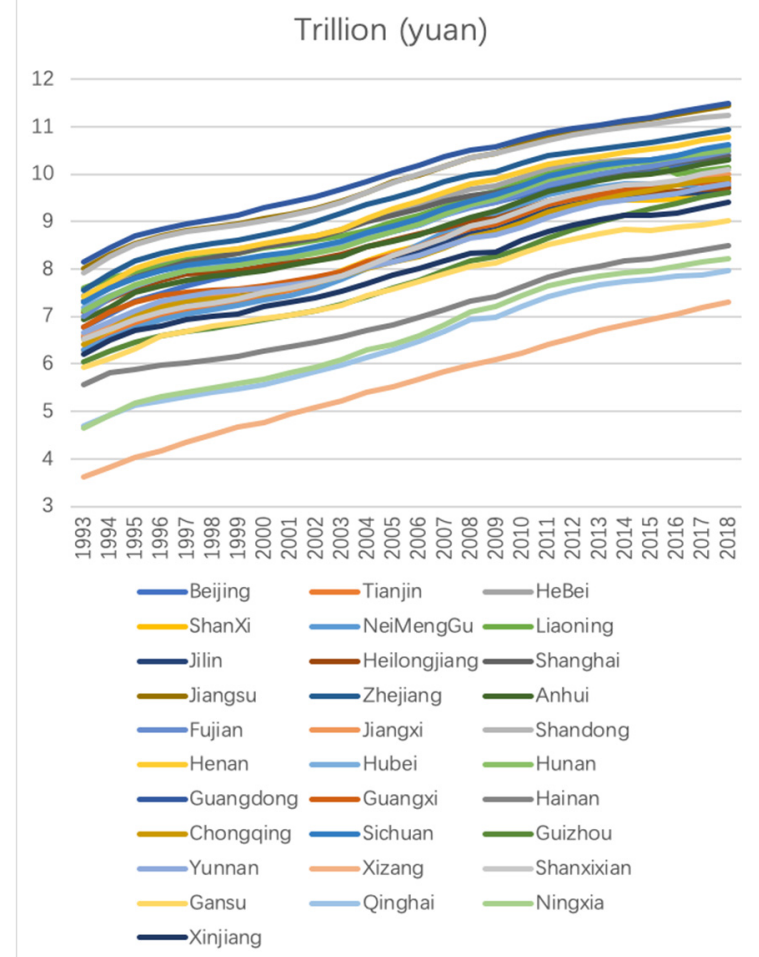

Figure 1. Chart of GDP variation trend of provinces and cities from 1993 to 2018

As can be seen from Figure 2, the development of freight volume of provinces and cities is not as regular as that of GDP, but the freight volume of provinces and cities in China shows an overall upward trend from 1993 to 2018 , and the growth in 2018 is significant compared with that in 1993. The freight volume of Anhui Province reached the overall peak in 2014, which was closely related to the rapid development of express industry in that year, but then decreased slightly. This kind of situation also appears in Shandong, Henan Province and so on. Through the above two figures, we can see the 
changes directly, but the relationship between them needs to be further explored.

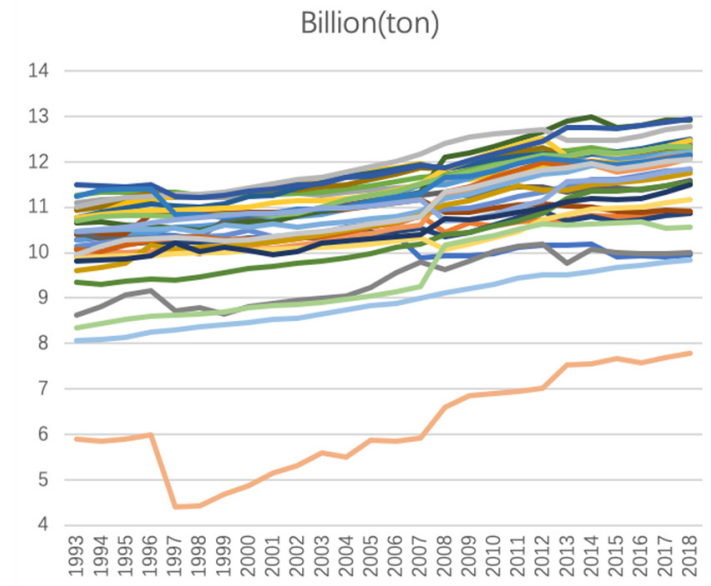

Figure 2. The change trend chart of freight volume of all provinces and cities from 1993 to 2018

Based on the above analysis, this paper selects the GDP and freight volume data of provinces and cities from 1993 to 2018. The Yangtze River Delta region, Pearl River Delta region, Beijing Tianjin Hebei region, northeast region and southwest region are regressed to study the relationship between freight volume and GDP in different regions.

TABLE I. ESTIMATION RESULTS OF FIXED EFFECT VARIABLE

\begin{tabular}{|c|c|c|}
\hline \multicolumn{1}{|c|}{ COEFFICIENT MODEL } \\
\hline \multirow{3}{*}{$\begin{array}{c}\text { Yangtze River } \\
\text { delta }\end{array}$} & City & Coefficient \\
\cline { 2 - 3 } & Shanghai & 2.001 \\
\cline { 2 - 3 } & Jiangsu & 2.334 \\
\hline Zhujiang delta & Zhejiang & 1.676 \\
\hline \multirow{3}{*}{$\begin{array}{c}\text { Beijing Tianjin } \\
\text { Hebei }\end{array}$} & Guangdong & 0.886 \\
\cline { 2 - 3 } & Beijing & -4.207 \\
\cline { 2 - 3 } & Tianjin & 3.33 \\
\hline \multirow{4}{*}{\begin{tabular}{c} 
Northeast \\
\cline { 2 - 3 }
\end{tabular}} & Hebei & 1.877 \\
\cline { 2 - 3 } & Liaoning & 1.994 \\
\cline { 2 - 3 } & Jilin & 3.871 \\
\hline \multirow{4}{*}{ Southwest } & Guangxi & 2.852 \\
\cline { 2 - 3 } & Chongqing & 1.226 \\
\cline { 2 - 3 } & Sichuan & 1.546 \\
\cline { 2 - 3 } & Guizhou & 1.461 \\
\cline { 2 - 3 } & Yunnan & 2.064 \\
\hline
\end{tabular}

It can be found from table 5 that the regional regression coefficient of the Yangtze River Delta is positive, but the value is relatively small, that is, the freight volume plays a small role in driving GDP, which is related to the strategic upgrading policy of the Yangtze River Delta region. It is experiencing the third transfer of the world economy, namely, a new round of industrial transfer characterized by service outsourcing and high-end manufacturing and technology R \& D link transfer. With the strategic upgrading of the Yangtze River Delta, the proportion of the tertiary industry in the region will further increase in the future, and the growth of freight demand will slow down.
Similarly, the industrial structure of the Pearl River Delta is developing towards the direction that the GDP of the tertiary industry is greater than that of the secondary industry and the primary industry. In recent years, the proportion of the tertiary industry in the Pearl River Delta region has gradually increased. In terms of 2018 , the total output value of the tertiary industry accounted for $80.98 \%$. Therefore, in the Yangtze River Delta and the Pearl River Delta region, due to the increasing proportion of the tertiary industry, the physical transportation is slightly reduced, and the driving effect of transportation on the economy is reduced.

In the Beijing Tianjin Hebei region, the correlation coefficient has a significant difference. There is a negative correlation between Beijing's freight volume and GDP. From the macro level, it is due to the continuous optimization of the industrial structure, the proportion of the primary and secondary industries continues to shrink, and the proportion of the tertiary industry continues to increase. In the first half of 2019 , the proportion of the three industrial structures in Beijing is 0.32:16.9:82.8, which shows once again the dominant position of Beijing's tertiary industry, which leads to the reduction of the demand for freight volume. Moreover, as the political and scientific and technological center of China, Beijing's high-tech financial industry has more economic growth advantages than the freight transportation industry. Compared with the transportation industry, the transportation industry has no competitive advantage. On the contrary, the limited resources used in freight transportation will reduce GDP. With its port advantages, Tianjin has a large freight volume, and its economic driving effect is obviously stronger than that of Beijing and Hebei Province. Especially since Binhai New Area has become a national strategy, Tianjin's economic growth has accelerated year by year. As far as the industrial structure of Hebei Province is concerned, Hebei does not have the advantage of resource agglomeration, and there are not as many talents and high-tech as Beijing and Tianjin.

It can be seen from the table that the coefficient of Northeast China is larger than that of the above regions, among which Jilin Province has the largest coefficient, which indicates that the impact of Northeast China's freight volume on GDP is relatively high ${ }^{[10]}$. Northeast China is located in the core area of Northeast Asia, adjacent to Russia, South Korea, Japan and other countries. It is an important hub and core area for China to open up to Northeast Asia. Its logistics industry develops rapidly, the industrial scale is also growing, and the logistics demand is also increasing.

It can be seen from the above table that the freight volume in Southwest China plays an important role in promoting the economy. This is because the development of the western region and the formation and implementation of China's global economic integration strategy have created unprecedented opportunities for the development of logistics industry in Southwest China. The railways, highways, ports and shipping in Southwest China are becoming more and more perfect. For example, the Nanning Kunming railway and the southwest highway to the sea have accelerated the integration of the rest of 
the world economy. Chongqing port has become a logistics hub in the upper reaches of the Yangtze River. In 2010, Chongqing first opened the route from Chongqing to Shenzhen Yantian port, and then transferred to sea going ships to Europe. In 2011, Chongqing launched the earliest China Europe train, namely "Chongqing" The "new Europe" freight train facilitates the export of Chongqing's cargo products to European countries; the throughput capacity of Guangxi's coastal ports and inland ports is also very significant; Yunnan and Sichuan have opened the "Yunnan Xinjiang Europe" and "Chengdu Xinjiang Europe" freight trains to Europe, while Guizhou has opened the "Guizhou Shenzhen Europe" sea rail intermodal freight train to the south in addition to integrating into Chongqing Xinjiang Europe railway channel in the north. All of these have increased the demand for freight transport and thus led to economic development.

\section{Conclusions AND SUggestion}

This paper first analyzes the trend of GDP and freight volume of each province, and finds that with the passage of time, the GDP and freight volume of all provinces and cities show an upward trend, but the rising range is not the same among different provinces and cities.

Then, this paper uses the fixed effect variable coefficient model to analyze the annual data of GDP and freight volume of major regions in China from 1993 to 2018. For specific regions, the Yangtze River Delta region and the Pearl River Delta region's freight volume has little driving effect on regional economic growth, the main reason is the adjustment of industrial structure, the proportion of tertiary industry is gradually increasing; the overall driving role of Beijing Tianjin Hebei region is relatively small, and the development of provinces and cities in the region is unbalanced. Among them, Beijing has high proportion of tertiary industry which leads to freight. There is a negative correlation between transportation volume and GDP; the northeast region, because of its geographical location, promotes the development of logistics industry and promotes the logistics demand, which has a greater driving effect; the southwest region also has a significant relationship between freight volume and economic development due to the development of its logistics industry.

According to the conclusion, the suggestions are as follows:

First of all, according to the impact of freight volume on GDP, all provinces and cities put forward the development policies in line with the regional transportation industry. For provinces and cities with a large proportion of GDP driving, they should continue to maintain the development momentum of the freight industry. The government should play an active role in guiding the development of industrial policies to promote the operation of modern logistics industry as much as possible. At the same time, it should moderately increase the strength of relevant infrastructure, give full play to the advantages of national strategic layout, reasonably plan logistics outlets, save resources waste caused by blind investment of enterprises, and indirectly provide logistics infrastructure for enterprises So as to enhance the freight volume, make the logistics development in turn promote the economic take-off, and finally achieve the virtuous cycle of logistics development and economic take-off.

Secondly, because the freight demand in the past mainly benefited from the primary and secondary industries, with the adjustment of industrial structure, the proportion of tertiary industry in various provinces and cities has gradually shown a rising trend, which requires all provinces and cities to find a suitable industrial structure model for their development, at the same time, the factors affecting the freight demand of transport enterprises are analyzed in depth. The government should also further formulate relevant policies, improve the construction of logistics information, promote the largescale development of the freight industry and improve its transportation efficiency. The government can also improve the specialization level of logistics industry by guiding small-scale enterprises to cooperate or merge with large-scale enterprises. The relevant departments of the logistics industry should also actively improve the logistics facilities and services, form the logistics industry chain, so as to enhance the added value of logistics.

\section{REFERENCES}

1. Tian Jun, Ran Zhongming. "Spatial econometric study on the impact of freight transportation on urban economic development-Based on the perspective of four regional differences"[J]. Inquiry into economic issues, 2019(11):76-93.

2. Li fen, Feng Fengling. "Research on the relationship between comprehensive transportation construction scale and economic growth - Empirical Analysis Based on VaR and VEC models "[J]. Journal of Hebei University of economics and trade, 2014,35 (3): 110-115.

3. TAPIO P."Towards a Theory of Decoupling:Degrees of Decoupling in the EU and the Case of Road Traffic in Finland Between 1970 and 2001"'J].Transport Policy, 2005, 12 (2) :137-151.

4. MCKINNON A C.'Decoupling of Road Freight Transport and Economic Growth Trends in the UK:An Explora tory Analysis"[J].Transport Reviews, 2007, 27 (1) :37-64.

5. VERNY J, GRIGENTIN C.“Container Shipping on the Northern Sea Route"[J].International Journal of Production Economics, 2009, 122 (1) :107-117.

6. Alises, A., J.M.Vassallo, and A.F.Guzmán, "Road Freight Transport Decoupling:A Comparative Analysis between the United Kingdom and Spain", Transport Policy,2014,32:186-193.

7. Ana Alises,José Manuel Vassallo. "Comparison of road freight transport trends in Europe. Coupling and decoupling factors from an Input-Output structural decomposition analysis"[J]. Transportation Research Part A,2015,82. 
8. Rong Chaohe. "Thoughts on the necessary adjustment of transportation stage division" [J]. Journal of Beijing Jiaotong University, 2016,40 (4): 122-129.

9. Yuan Yunxiao, Wang Baohai. "An empirical analysis of the impact of freight volume on Regional
Economic Development -- Based on the panel data of 31 provinces and cities in China "[J]. China market, 2018 (07): 14-17, 42.

10. Cheng Cheng. "Screening and prediction of regional freight volume in three eastern provinces" [D]. Jilin University, 2013 